\title{
Effect of casting defects and roller burnishing on fatigue properties of a cast aluminum alloy AC4CH
}

\author{
Y. Nakamura ${ }^{1}$, H. Masuda ${ }^{2}$, T. Shimizu ${ }^{1}$, M. Nakajima ${ }^{1}$ \\ \& Y. Uematsu ${ }^{3}$ \\ ${ }^{1}$ Department of Mechanical Engineering, \\ Toyota National College of Technology, Japan \\ ${ }^{2}$ Toyota National College of Technology, Japan \\ ${ }^{3}$ Department of Mechanical and Systems Engineering, \\ Gifu University, Japan
}

\begin{abstract}
In order to clarify the effect of casting defects on the high cycle fatigue properties, rotary bending fatigue tests were carried out on a cast aluminum alloy, JIS AC4CH, with two different levels of defect size. As a result of fatigue tests, the fatigue strength decreased with increasing the defect size. The fatigue limits were estimated by the $\sqrt{\text { area }}$ parameter model and compared with experimental values. The maximum defect size evaluated by the extreme value statistics was used in the prediction. The predicted values of fatigue limits for specimens with the different defect sizes were not in good agreement with the experimental values. In addition, the effects of the roller burnishing process on surface conditions and fatigue properties were also investigated. Vickers' hardness and compressive residual stress on the specimen surface were increased by the burnishing process. An improvement of fatigue property was found in the burnished specimen. It is due to the disappearance of casting defect on the specimen surface, and increase of hardness and compressive residual stress.

Keywords: fatigue, cast aluminium alloy, casting defect, roller burnishing, statistics of extreme value.
\end{abstract}




\section{Introduction}

Cast aluminum alloys have been widely used for mechanical components particularly in automotive industries, because its flexibilities in fabrication and cost saving as compared with wrought alloys [1-3]. However, it is well-known that the fatigue fractures of cast aluminum alloys are due to the casting defect in many cases $[4,5]$. Their fatigue strengths strongly depend on the number and the size of casting defects. In this study, rotary bending fatigue tests were performed on a cast aluminum alloy with two different defect sizes, and the effect of the defect size on fatigue behavior was investigated.

Furthermore, the roller burnishing process has been used to improve the surface conditions such as roughness and hardness, and to give a compressive residual stress. It is also expected to improve the fatigue property due to the disappearance of casting defects on the specimen surface. Fatigue tests were also carried out on the burnished specimen to investigate the effect of burnishing on the fatigue behavior.

\section{Experimental procedure}

\subsection{Material and specimen}

The material used in this study was a cast aluminium alloy, JIS AC4CH-T6, whose chemical composition (mass\%) is listed in Table 1. The fatigue test specimens were machined from different heights of boat-shaped aluminum castings as shown in Fig.1. The specimens machined from the upper part of aluminum castings were designated as the Type $U$ specimen, and obtained from lower part of the aluminium castings were the Type L specimen. The mechanical properties of the material are shown in Table 2. Figure 2 shows the specimen configuration, whose central part of the specimen surface was buff-finished after

Table 1: $\quad$ Chemical composition (mass \%).

\begin{tabular}{|c|c|c|c|c|c|c|}
\hline $\mathrm{Mg}$ & $\mathrm{Fe}$ & $\mathrm{Ti}$ & $\mathrm{Ni}$ & $\mathrm{Cr}$ & $\mathrm{Sr}$ & $\mathrm{Al}$ \\
\hline 0.39 & 0.06 & 0.13 & 0.003 & 0.001 & 0.0042 & Bal. \\
\hline
\end{tabular}

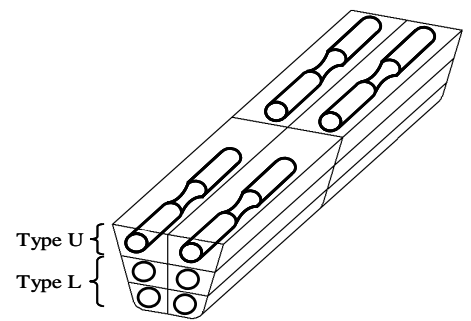

Figure 1: $\quad$ Position of the specimens in the boat-shaped aluminium casting. 
polishing by the emery paper with the grade of \#2000. Type L specimens finished by roller burnishing were also prepared as burnished specimen and carried out on fatigue tests.

Table 2: $\quad$ Mechanical properties.

\begin{tabular}{|c|c|c|c|c|c|}
\hline $\begin{array}{c}0.2 \% \text { proof } \\
\text { stress }\end{array}$ & $\begin{array}{l}\text { Tensile } \\
\text { strength }\end{array}$ & Elongation & $\begin{array}{l}\text { Young's } \\
\text { modulus }\end{array}$ & \multicolumn{2}{|c|}{$\begin{array}{c}\text { Vickers hardness } \\
H V\end{array}$} \\
\hline$\sigma_{0.2}(\mathrm{MPa})$ & $\sigma_{\mathrm{B}}(\mathrm{MPa})$ & & $E(\mathrm{GPa})$ & Type L & Type U \\
\hline 264 & 324 & 11 & 75 & 122 & 115 \\
\hline
\end{tabular}

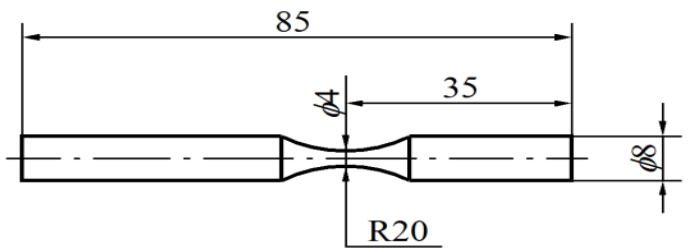

Figure 2: Specimen configuration.

Figure 3 shows microstructures of the Type $\mathrm{L}$ and Type $\mathrm{U}$ specimens. Both specimens compose of a dendritic structure, and the size of casting defects in the Type $\mathrm{U}$ specimen is larger than that in the Type $\mathrm{L}$ specimen.

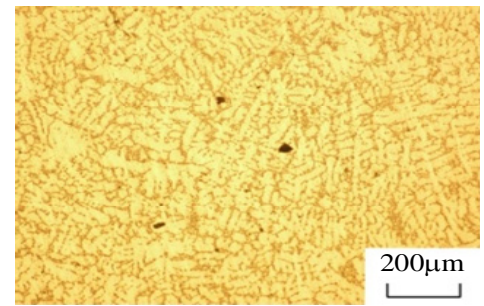

(a) Type L.

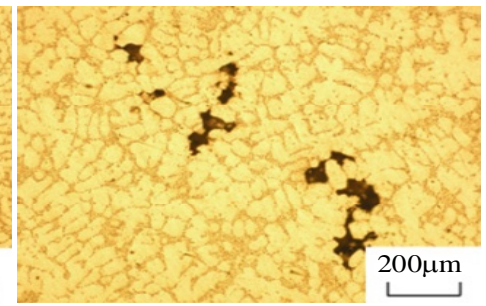

(b) Type U.

Figure 3: $\quad$ Microstructures.

\subsection{Procedure}

Fatigue tests were performed using cantilever-type rotary bending fatigue testing machines operating at a frequency of $53 \mathrm{~Hz}$ in laboratory air. After experiments, fracture surfaces were examined using a scanning electron microscope (SEM). 


\section{Results and discussion}

\subsection{Surface condition}

The hardness distribution of the burnished specimen is shown in Fig.4. The hardness at the surface is HV152 for the burnished specimen, while HV122 for the untreated specimen. The increase of hardness was due to the work hardening by burnishing. The thickness of the layer can be estimated to be about $80 \mu \mathrm{m}$ by the change in hardness.

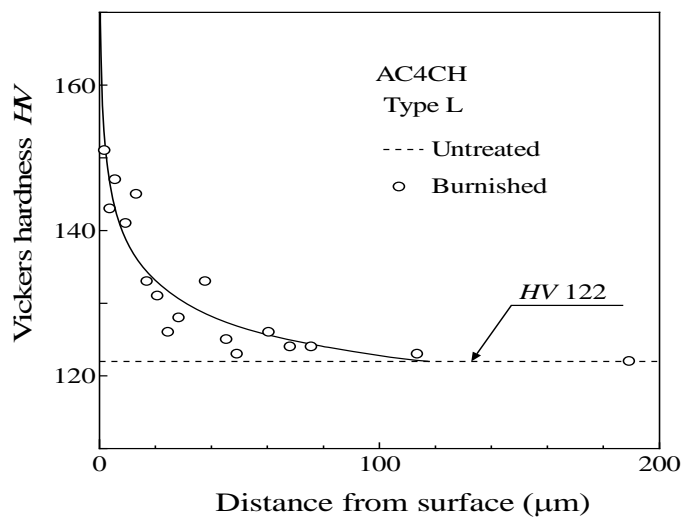

Figure 4: $\quad$ Hardness profile.

Surface roughness was measured and the results are given in Table 3. The average roughness, $R_{\mathrm{a}}$, and the maximum height, $R_{\mathrm{y}}$, of the burnished specimens indicate higher values than those of the Type $L$ specimen which is buff-finished. Residual stresses of the burnished and Type L specimens measured by X-ray diffraction method are listed in Table 3. Average residual stresses of the burnished and Type L specimens at the surface were $-132 \mathrm{MPa}$ and $-35 \mathrm{MPa}$, respectively.

Table 3: $\quad$ Surface roughness and residual stress.

\begin{tabular}{|c|c|c|c|}
\hline \multirow{2}{*}{ Specimen } & \multicolumn{2}{|c|}{ Surface roughness } & Residual stress \\
\cline { 2 - 3 } & $R_{\mathrm{a}}(\mu \mathrm{m})$ & $R_{\mathrm{y}}(\mu \mathrm{m})$ & $\sigma_{\mathrm{a}}(\mathrm{MPa})$ \\
\hline Type L & 0.03 & 0.77 & -35 \\
\hline Burnished & 0.04 & 1.24 & -132 \\
\hline
\end{tabular}

\section{$3.2 S-N$ characteristics}

Figure 5 indicates the $S$ - $N$ curves of the Type L, $\mathrm{U}$ and the burnished specimens. Data points with arrow indicate the run-out specimen at $10^{8}$ cycles. The Type U 
specimen exhibited lower fatigue strength than the Type L specimen, because large casting defects existed in the specimens and played a role as a crack starter.

In addition, it is clear that the fatigue strengths of the burnished specimen were improved in comparison with those of the Type $U$ and $L$ specimens. The improvement of fatigue strength was due to the work-hardening, compressive residual stress and disappearance of casting defects at the surface layer induced by burnishing.

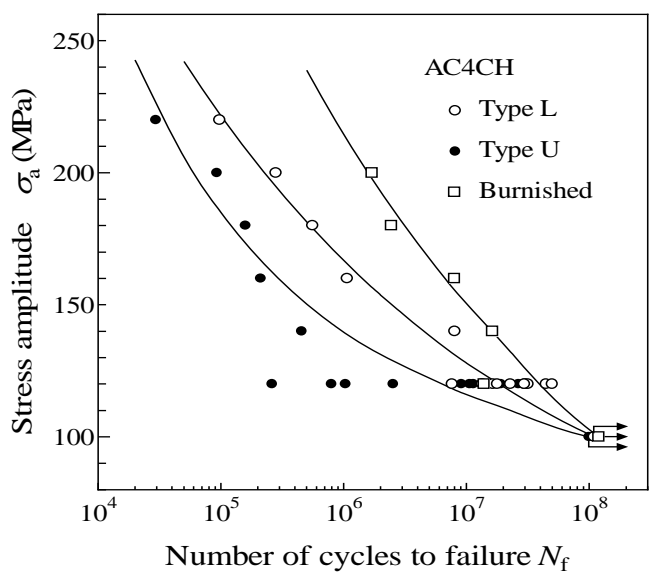

Figure 5: $\quad S-N$ diagram.

Since the fatigue strengths at $10^{7}$ cycles were the same in the Type $U$ and Type L specimens, fatigue tests were performed at a stress level of $120 \mathrm{MPa}$ allocating 10 specimens to clarify the fatigue life distribution. The results are plotted on a log-normal probability papers shown in Fig.6. The fatigue lives of

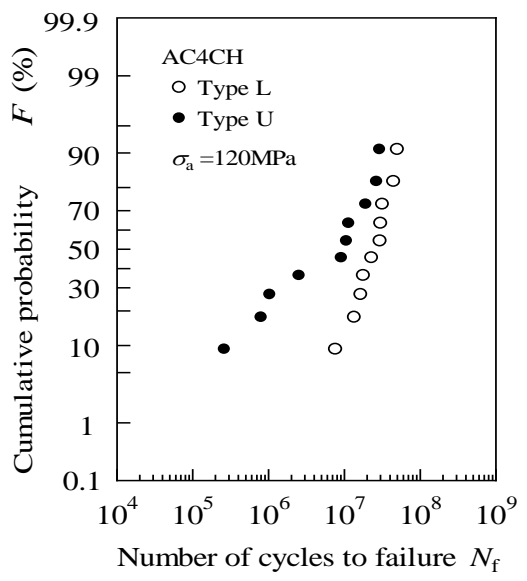

Figure 6: $\quad$ Fatigue life distributions of Type L and Type U specimens plotted on a log-normal probability paper. 
the Type U specimen are markedly scattered, suggesting the shorter than those of Type L specimen and fatigue life strongly depends on the size and the number of casting defects.

\subsection{Fracture surfaces}

Fatigue fracture surfaces near crack initiation sites in the Type L, Type U and burnished specimens are revealed in Fig.7. In the Type L specimen, a cluster of

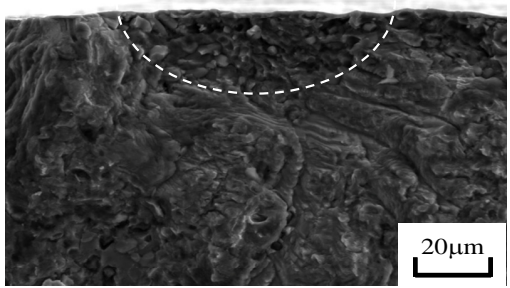

(a) Type L $\left(\sigma_{\mathrm{a}}=200 \mathrm{MPa}, N_{\mathrm{f}}=2.81 \times 10^{5}\right)$

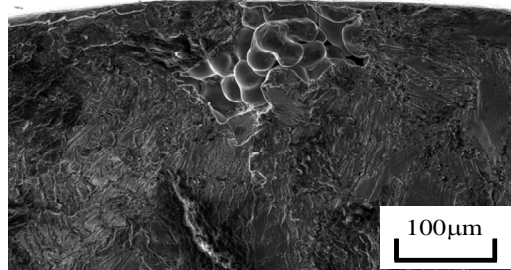

(b) Type U $\left(\sigma_{\mathrm{a}}=200 \mathrm{MPa}, N_{\mathrm{f}}=9.29 \times 10^{4}\right)$

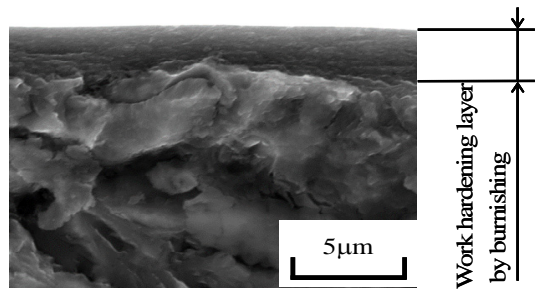

(c) Burnished. $\left(\sigma_{\mathrm{a}}=180 \mathrm{MPa}, N_{\mathrm{f}}=2.45 \times 10^{6}\right)$

Figure 7: $\quad$ SEM micrographs showing crack initiation site.

pores, which is a casting defect, was seen near crack initiation site (Fig. 7(a)), suggesting fatigue crack initiation from the pores. Casting defect was also found at the crack initiation site in the Type U specimen (Fig. 7(b)). The defect size in the Type U specimen was larger than that of the Type L specimens. On the other hand, in the burnished specimens (Fig. 7(c)), casting defects was not found at crack initiation site. This implies that the improvement of fatigue strength in the burnished specimen was also due to the disappearance of casting defects at the surface layer of specimen.

\subsection{Estimation of fatigue limit by statistics of extremes}

The maximum size of casting defects $\left(\sqrt{\text { area }}_{\max }\right)$ was estimated using the extreme statistics in the Type $\mathrm{L}$ and $\mathrm{U}$ specimens. Figure 8 shows the extreme value distributions of the casting defects in both specimens. The standard volume, $V_{0}$, was calculated by the product of the standard area which is the minimum cross section area of specimen, $S_{0}$, and the mean casting defect size obtained from the 


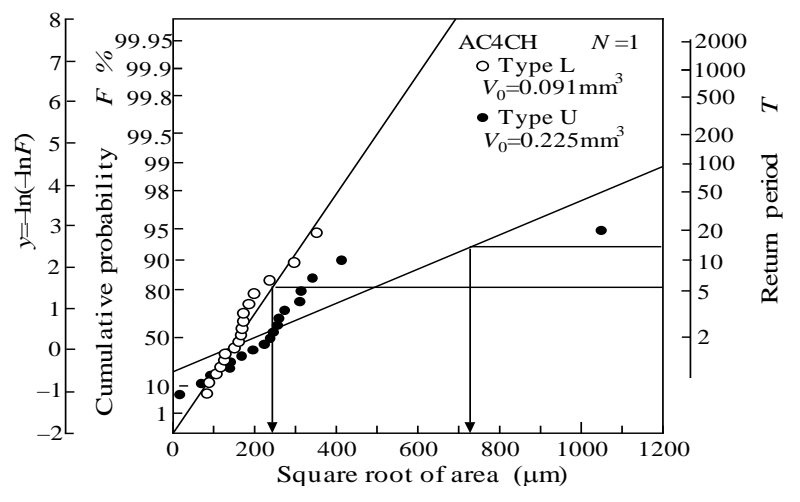

Figure 8: $\quad$ Statistics of extreme distribution of casting defects.

extreme value distribution, i.e. this value represents the supposed thickness of the standard area. The control volume, $V$, was calculated as the volume at which the stress amplitude, $\sigma_{\mathrm{a}}$, is more than $90 \%$ of the maximum stress amplitude in the stress gradient. The maximum defect sizes calculated in the Type $L$ and Type $\mathrm{U}$ specimens are $243 \mu \mathrm{m}$ and $729 \mu \mathrm{m}$, respectively. Thus, the estimated maximum size of casting defect in the Type $U$ specimen was much larger than that of the Type L specimen.

Based on above values, the fatigue limits of the Type $U$ and $L$ specimens were predicted by following equations:

$$
\begin{gathered}
\sigma_{\mathrm{w}}=1.43(120+H V) /(\sqrt{\text { area }})^{1 / 6} \\
\sigma_{\mathrm{w}}=1.43\left(120 E_{\mathrm{Al}} / E_{\mathrm{St}}+H V\right) /(\sqrt{\text { area }})^{1 / 6}
\end{gathered}
$$

where, Young's modulus of aluminum alloy, $E_{\mathrm{Al}}$, is 75GPa (see Table 2) and Young's modulus of steel, $E_{\mathrm{St}}$, is $206 \mathrm{GPa}$.

$$
\sigma_{\mathrm{w}}=1.43(75+H V) /(\sqrt{\text { area }})^{1 / 6}
$$

Eq.(1) was proposed by Prof. Murakami to estimate the fatigue limit of steels which have small defects and non-metallic inclusions on the surface of material [6]. Eq.(2) was proposed by Prof. Noguchi [7]. This equation is able to estimate the fatigue limit of non-ferrous metal materials. And eq. (3) was proposed by Prof. Ueno to estimate the fatigue limit of the cast aluminium alloy [8]. These three equations are based on the root area parameter model by Prof. Murakami, and are able to predict the fatigue limit for specimens which have defects at the surface such as the Type $U$ and $L$ specimens. In addition, the equations are not suitable for the surface-treated materials. The burnished specimens do not have casting defects at the surface due to the disappearance of casting defects by burnishing process. Thus, the three models can not apply to the burnished specimen. The results are given in Table 4. As seen in the table, estimated 
Table 4: $\quad$ Comparisons of prediction fatigue limit with experimental results.

\begin{tabular}{|c|c|c|c|c|c|c|}
\hline \multirow{2}{*}{ Material } & \multirow{2}{*}{$\begin{array}{c}\sqrt{\text { area }}_{\max } \\
(\mu \mathrm{m})\end{array}$} & \multirow{2}{*}{$\begin{array}{c}\text { Hardness } \\
\text { HV }\end{array}$} & \multicolumn{4}{|c|}{ Prediction of fatigue limit (MPa) } \\
\cline { 4 - 7 } & & & Eq.(1) & Eq.(2) & Eq.(3) & Experimental \\
\hline Type L & 243 & 122 & 139 & 95 & 113 & 100 \\
\hline Type U & 729 & 115 & 112 & 76 & 91 & 100 \\
\hline
\end{tabular}

fatigue limits calculated by Eq.(1) are 139MPa for the Type L specimen and $112 \mathrm{MPa}$ for the Type $U$ specimen, while the fatigue limits obtained by experiments are $100 \mathrm{MPa}$ in both specimens. Thus, the prediction seems to be overestimated. On the other hand, estimated fatigue limits calculated by Eq.(2) are lower than experimental values, indicating that prediction give the conservative values. Estimated fatigue limits calculated by Eq.(3) most close to the experimental values. However, the prediction in the Type L specimen seems to be overestimated. If the predicted values are used as the design value, the predictions are necessary to give the conservative value. Based on these results, therefore further studies are needed for the better estimation of the fatigue limit.

\section{Conclusions}

In the present study, rotary bending fatigue tests were carried out on a cast alunimum alloy, JIS AC4CH, with two different levels of the defect size, that is , Type $\mathrm{L}$ and $\mathrm{U}$. In addition, roller burnishing was performed to investigate the effects of casting defects and of roller burnishing on the high cycle fatigue properties. The results obtained are summarized as follows;

(1) The hardness was increased by burnishing. It was due to the work hardening. The compressive residual stress on the surface of specimen was also increased from $-32 \mathrm{MPa}$ to -132 .

(2) The fatigue strength of the Type U specimen was lower than that of the Type $\mathrm{L}$ specimen. The burnished specimen exhibited higher fatigue strength than the Type L and U specimens.

(3) Fatigue lives of the Type U specimen indicates large scatter than those of the Type L specimen.

(4) According to the estimation of fatigue limit by statistics of extremes, fatigue limits calculated by the equations to estimate the fatigue limit were not in good agreement with the experimental results.

\section{References}

[1] Shiozawa, K., Nishino, S., Tohoda, Y., Sun, S.M., Transactions of the Japan Society of Mechanical Engineers, Series A, 60(571), pp. 663-668, 1994. 
[2] Ikeda, H., Toriyama, T., Murakami, Y., Transactions of the Japan Society of Mechanical Engineers, Series A, 57(538), pp. 1320-1325, 1991.

[3] Masaki, K., Ochi, Y., Matsumura, T., Sano, Y., Materials Science and Engineering A, 468-470(15), pp. 171-175, 2007.

[4] Zhu, X., Shyam, A., Jones, J.W., Mayer, H., Lasecki, J.V., Allison, J.E., International Journal of Fatigue, 28, pp. 1566-1571, 2006.

[5] Nakamura, Y., Sakai, T., Hirano, H., Ravi Chandran, K.S., International Journal of Fatigue, 32, pp. 621-626, 2010.

[6] Murakami, Y., Kodama, S., Konuma, S., Transactions of the Japan Society of Mechanical Engineers, Series A, 54(500), pp. 688-696, 1988.

[7] Noguchi, H., Morishige, K., Fujii, T., Kawazoe, T., Hamada, S., Proceedings of the 56 $6^{\text {th }}$ JSMS Annual Meetings, 613, pp. 137-138, 2007.

[8] Ueno, A., Nishida, M., Miyakawa, S., Yamada, K., Kikuchi, S., Proceedings of The 31 ${ }^{\text {st }}$ Symposium on Fatigue, 36, pp. 159-163, 2012. 